\title{
Management of composite hand defects using free rectus abdominis muscle flap
}

\author{
Sameh M El-Taher, MD; Hazem Maher Aly, MD \\ Department of Plastic \& Reconstructive Surgery, Ain Shams University, \\ Cairo, Egypt.
}

\begin{abstract}
Background: Hand injuries are the main cause of work-related disability in young adults. Wound coverage after a complete degloving injury of the hand and fingers is of the most difficult problems in hand surgery. The goal of treatment is to cover the hand defects with pliable, sensitive, and cosmetically similar tissues that will allow early rehabilitation and protect the underlying structures. The covering flap was chosen according to the functional and aesthetic needs with less donor site morbidity. Combined defects can be reconstructed with composite tissue flaps. So the aim of this study is to use the rectus abdominis muscle free flap for reconstructing the hand defects to improve the functional hand disability, with better cosmetic shape and less donor site morbidity.

Patients and methods: 18 patients with acute traumatic hand defects were enrolled in this study. The follow up time ranged from 6-9 months postoperatively and were reconstructed by free rectus abdominis muscle flap and converge of the muscles by STSG

Results: No flap loss occurred in this study. The scars healed well, and the patient was fully ambulant. Complication included; hematoma, ischemia, infection and disruption. The STSG showed $10 \%$ loss in one case and 30\% loss in another case. As for the donor site, early complication showed seroma in 2 cases and wound disruption in one case which was left to heal conservatively.

Conclusion: Adequate coverage of soft tissue associated with major hand injuries ensures primary healing, protects the reconstruction of the underlying structures and facilitates early rehabilitation.
\end{abstract}

\section{Introduction:}

Hand injuries represent a large percentage of cases in Emergency departments. The hand is important for adaptive skills and functions. Therefore its injuries have both personal and social effects. They can also have an economic importance by affecting the ability to perform work and are the main cause of work related disability especially in young adults. ${ }^{1}$ The severities of these injuries influence the degree of long-term disability and determine whether subsequent return to work is possible in its original or modified form. So, psychological preparation for the future level of disability could identify retraining these patients to form new skills. ${ }^{2}$
Trauma to the upper extremity is more complex to manage, due to other circumstances such as the patient's status (shock, abdominal injury). As a result of the structural complexity of the upper extremity, tissue defects often result in exposure of vital structures such as bone, nerve, tendons and blood vessels. ${ }^{1}$ The reconstructive ladder for soft tissue coverage using simple techniques such as skin grafting may not provide optimal coverage for a particular defect. ${ }^{3}$ Furthermore, the requirement of functional restoration can only be treated by tissue transfer using a composite transplantation (skin, fascia, muscle, bone or a combination of tissues). Also, the cosmetic appearance of the hand is often restored by composite tissue transplantation. ${ }^{4}$ 
Regional flaps can be used to cover the hand defects. The morbidity of any local or regional flap must be considered, because the hand is highly visible, the cosmetic aspect of local and regional flaps must be considered as well. ${ }^{3}$ The use of distant flaps (abdominal and groin flaps) for covering of hand defect had less popularity, as for their co-morbid conditions e.g. long duration before separation reaching up to 3 weeks with higher incidence of infection, beside the bulking non cosmetic appearance of it, which will need other sessions of debulking.

The large post-traumatic tissue loss may aggravate the initial lesion, with frequent exposure of bone, joint and blood vessels leading to the amputation of the limb in most cases. However, the timing of these procedures is still a matter of controversy. ${ }^{5}$ Godina et al ${ }^{6}$ recommended immediate soft tissue coverage after aggressive debridement and fracture stabilization, within the first $24-72 \mathrm{~h}$. This aims to prevent the drawbacks of open wound therapy so many distant flaps can be used to cover the defect primarily, for example; random abdominal wall flap which is known for its simplicity, and suitability for coverage of the entire hand and fingers. A disadvantage is that the covered hand is too bulky. Also, the fixation of the hand to the abdominal tissue pocket results in stiffness of the hand, elbow and shoulder joints. Fibrosis, infection and tissue edema may complicate local flap transpositions or microsurgical transplantations performed beyond a period of 72 hours. Early wound coverage reduces pain, infection, and the number of surgical procedures and the cost of treatment. ${ }^{4}$ Certain wounds may be covered with a flap from the same or opposite extremity e.g. radial forearm flap, posterior interosseous flap. ${ }^{7}$

The salvage rate and functional rehabilitation in these injuries has improved since the use of new methods, microsurgical techniques allowing a definitive reconstruction of this combined defects i.e. the use of a free flap for many hand wounds.

Composite tissue transfer offers the ability to reconstruct functional deficits with flaps containing skin, bone, joint, and reinnervated muscle. Almost any composite defect of the upper limb can now be reconstructed with a free tissue transfer. The selection of which muscle to transfer is based on the experience of the surgeon, but the "workhorses" in large wounds of the upper extremity are the latissimus dorsi ${ }^{9}$ and rectus abdominis muscle flaps. ${ }^{10}$ Smaller defects can be covered with either a portion of one of these muscles or a smaller muscle flap, such as the serratus anterior or gracilis muscle. The rectus abdominis is a muscle widely used in microsurgery; this muscle is on the anterior abdominal wall and runs from the medial lower ribs to the pubis. It lies in a sheath composed anteriorly of continuations of the external and internal oblique muscle layers. The posterior sheath is a continuation of the transversus abdominis, but in the lower abdomen, it is thin (below the linea semicircularis). This is a fairly large muscle, and it has a reliable vascular pedicle based on the deep inferior epigastric system. ${ }^{10}$

The pedicle is fairly long ( 5 to $7 \mathrm{~cm}$ ), and its caliber is fairly large $(2.5$ to $3 \mathrm{~mm})$. The rectus abdominis muscle will cover most defects of the hand and forearm, and it will cover large defects of the forearm if most of the muscle is harvested. The advantages of this muscle are that it has a reliable vascular pedicle and may be taken with the patient supine. The disadvantage of this muscle is that a hernia can result from its harvest if fascia is injured or corrected improperly or if the anterior sheath is weak. For coverage of the upper extremity, this muscle is usually harvested without a skin paddle and covered with a split-thickness skin graft. ${ }^{11}$

So in this study we use the rectus abdominis muscle free flap for reconstructing the immediate traumatic composite hand defects aiming to prevent and minimize the functional hand disability, with better aesthetic appearance and minimal donor site morbidity.

\section{Patients and methods:}

Between March 2006 and March 2009, in the Plastic and Reconstructive Surgery Department, Ain Shams University Hospitals, 18 patients with acute traumatic hand defects were enrolled in this study. The follow up time ranged from 6-9 months postoperatively. They were 15 males and 3 females, age ranging from 
12 - 58 years (average 32 yrs). 11 patients were manual workers. 8 patients were smokers. 3 patients were hypertensive. 10 patients had associated major non life threatening injuries (fracture femur or fracture pelvis). The etiology of the traumatic soft tissue loss and bony defects was avulsion (3 cases), degloving ( 2 cases) and crushing injuries (13 cases). The site of injury was on the palmar aspect (6 cases) and dorsal aspect (12 cases). 5 cases had injury extending to the forearm.

They were reconstructed by free rectus abdominis muscle harvested either by lower abdominal incision (10 patients), vertical lazy $\mathrm{L}$ incision (6 patients) or endoscopic (2 patients). The rectus abdominis muscle flap size differed in its length and width according to the age, sex and occupation. The dimensions of the rectus abdominis muscle ranged from 28 to $35 \mathrm{~cm}$ in length and 7 to $10 \mathrm{~cm}$ in width.

After harvest, the length of the muscle shortens and contracts approximately 30 percent from its original length. Similarly, the width of the muscle increases by approximately 25- 50 percent. This must be taken into consideration when designing the flap to cover the entire recipient area defect.

Microvascular anastomosis was done at the same crushed vessel (injured vessel) about 5 $\mathrm{cm}$ proximal to the critical zone of injury. These recipient vessels were radial artery (10 cases) and ulnar artery (8 cases). Immediate reconstruction was done in 15 patients whereas delayed reconstruction was done in 3 patients.

\section{Preoperative planning:}

Full history was recorded for each patient to clarify the etiology of the defect, age, weight of the patient, special habits of medical importance (e.g. smoking, alcohol, addict) and concomitant diseases (e.g. Diabetes mellitus, hypertension and other cardiac or vascular disease). General and local examinations of the patient were done. Evaluation of each hand defect was performed considering the following:

- Amount of the tissue loss (dimension, depth and extension of the defect).

- Neurovascular damage.

- Recipient site condition.

- Allen's test to assess the vascular supply of the hand.
Laboratory studies included:

- Complete blood count (CBC).

- Blood sugar.

- Renal function tests.

- Liver function tests.

- Prothrombin time and activated partial thromboplastin time.

- Arm and/or hand radiographs.

- Chest radiograph.

- Doppler or angiography to assess the vascular pattern of the upper extremity once needed in those patients with difficult clinical evaluation of the limb vascularity and/or patients with heavy trauma with a suspect of vascular injury.

- ECG, ECHO cardiograph

- Arteriogram

\section{Operative procedures:}

Two teams will operate synchronously with the patient in prone position with the mutilated hand extended on a hand table. This allows a simultaneous team approach so that one team can harvest the rectus muscles while the other team is debriding and preparing the wound and recipient artery and veins. Furthermore, the micro vascular anastomosis can be done without any additional repositioning of the patient. With tourniquet inflated, aggressive debridement of all nonviable and necrotic tissue is the important step before tissue transfer.

After that fixation of fractured bone and bone graft is done if needed. Tendon grafts and/or tendon transfer were done in case of tendon loss and nerve graft or repair is done for injured nerves. The tourniquet was then released to ensure vascularity of all residual structures and remove any residual devitalized tissue and ensuring blood flow in the recipient vessels.

\section{Surgical harvest of rectus abdominis:}

This included a lower abdominal incision, dissection down to the anterior rectus sheath, exposure of the rectus abdominis sheath and muscle with sufficient retraction. We avoided any additional incisions and kept the umbilicus attached to the abdominal skin flap and abdominal wall. The flap was delivered through the wound and the pedicle was dissected keeping the surrounding fat. The anterior rectus sheath was repaired longitudinally in two layers 
to avoid abdominal wall laxity or herniation. The abdominal skin flap was closed over a suction drain, and the skin incision was closed in two layers with absorbable suture.

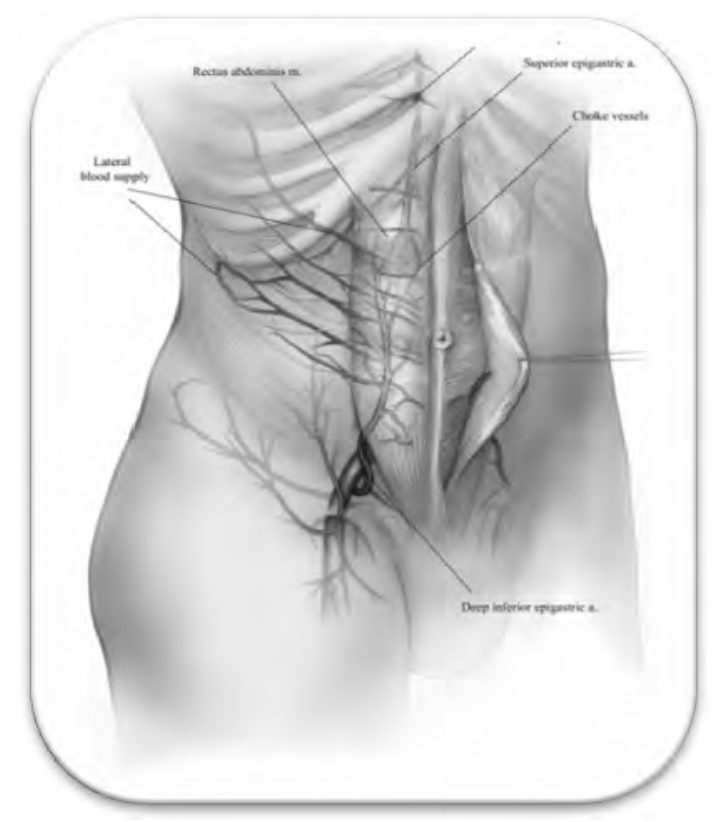

Figure (1): Showing the rectus abdominis muscle and its vascular territory. ${ }^{10}$

Endoscopic harvest of rectus abdominis:

A standard laparoscopic setup was used for dissection. This included light source, endoscopic video camera and video monitor. Special retractors were used during this procedure. Disposable laparoscopic instruments including $10 \mathrm{~mm}$ ports, $10 \mathrm{~mm}$ Hassan-type ports and $5 \mathrm{~mm}$ ports, blunt and pointed forceps, clip applier and scissors were used. To minimize spark gap cautery injuries and direct extension of thermal or electrical injuries to the muscles or the pedicle the scissors were bipolar. The endoscope was a $10 \mathrm{~mm}$, full length rigid scope with a 30 degree viewing angle. All microvascular anastomoses of one artery and one vein were performed as interrupted endto-side anastomoses using 10/0 black nylon sutures with lancet point $3 / 8$ circle needle.

\section{Postoperative care:}

In the post operative period the patient received: systemic broad-spectrum antibiotics which were followed later by the oral form, low molecular weight heparin (clexan 40-80 IU) twice daily for 5 days after the fifth day and $4000 \mathrm{ml} \mathrm{IV} \mathrm{fluids/day} \mathrm{in} \mathrm{the} \mathrm{form} \mathrm{of}$ lactated Ringer solution which was decreased gradually starting from the sixth day to be completely withdrawn on the 5th postoperative day too.

Flaps were monitored for color, moisture, texture, temperature and fullness every two hours in the first two days and four times per day until 4th day postoperatively with the aid of a Doppler probe to check the patency of the micro anastomoses if a graft was applied immediately. STSG usually was done on the 4th day postoperative.

\section{Follow-up care and rehabilitation:}

Contour and stability of the reconstruction were observed after two weeks and at 6 and 9 months postoperatively. Active mobilization of the injured limb commenced as soon as the stability of the soft tissue cover was ensured. This included stability of all vascular and microvascular anastamoses as well as the establishment of early healing of any skin grafts. An element of passive mobilization was necessary when nerves or tendons were injured. Therapy, appropriate for the protection of repaired tendons, should be incorporated. 


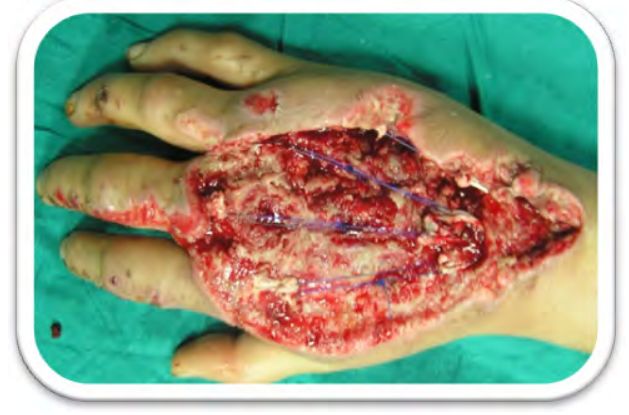

(A)

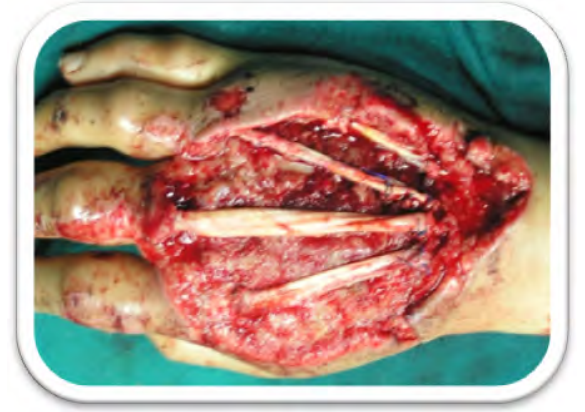

(C)

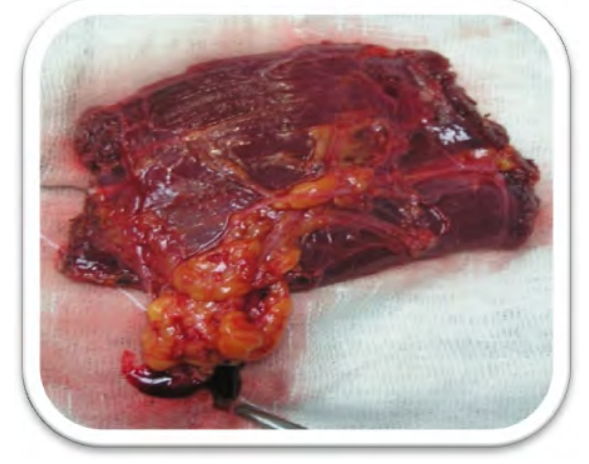

(E)

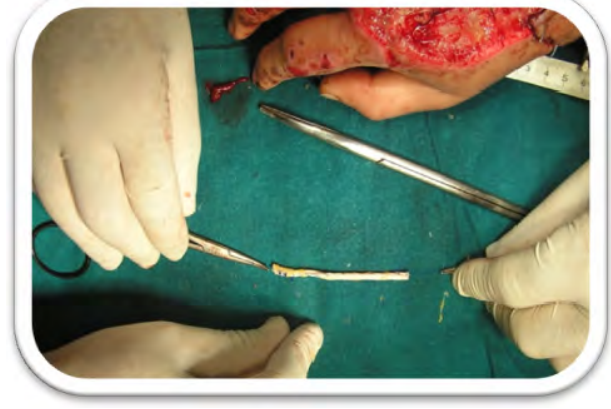

(B)

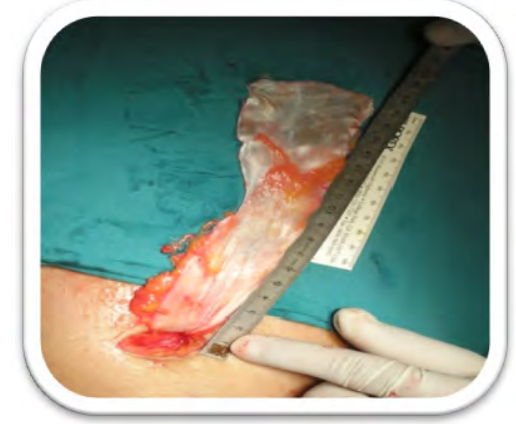

(D)

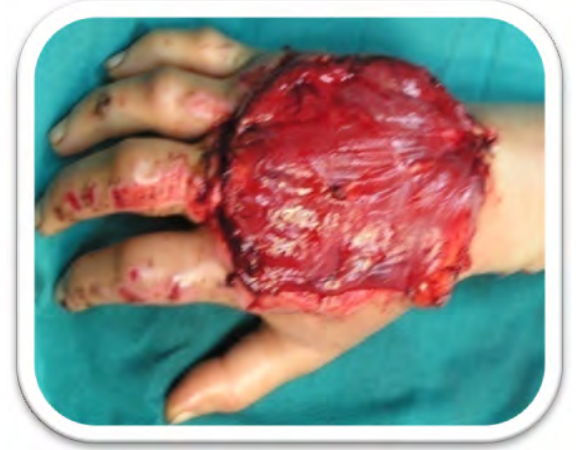

(F)

Figure (2): Showing post traumatic defect on the dorsum of the hand with subsequent reconstructive stages from tendon graft to free rectus coverage.

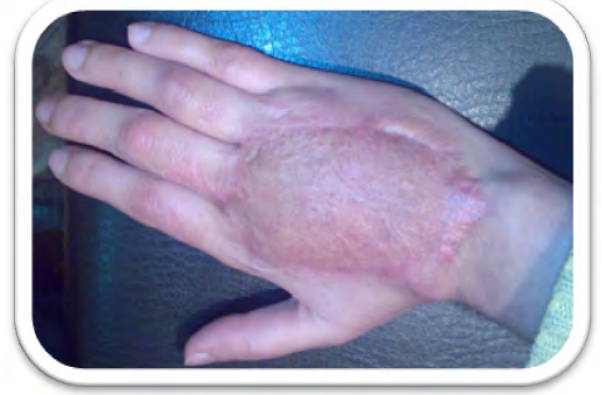

(A)

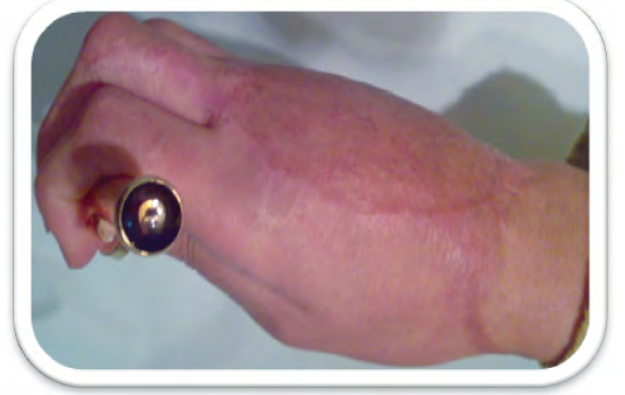

(B)

Figure (3): Showing results of follow up rehabilitation on the same patient in figure (2). 


\section{Results:}

No flap loss occurred in this study. Follow up period was $6-9$ months, average 7 months. Timing of the harvest ranged from $75-120$ minutes (average 90 minutes) in the traditional lower abdominal incision while with the endoscopic harvest it took 150 minutes in one case and 180 minutes in the second case. Total operative time was 270 - 360 (average 300) minutes according to the severity and the extent of trauma. The scars healed well, and the patients were fully ambulant.

Early recovery time for patients was 1-3 days. Post operative hospital stay ranged from 7 - 14 days (average 10 days). Immediate STSG was done in (10 cases) while delayed STSG was done in (8 cases). In all patients, immediately after the muscle free flap transefer

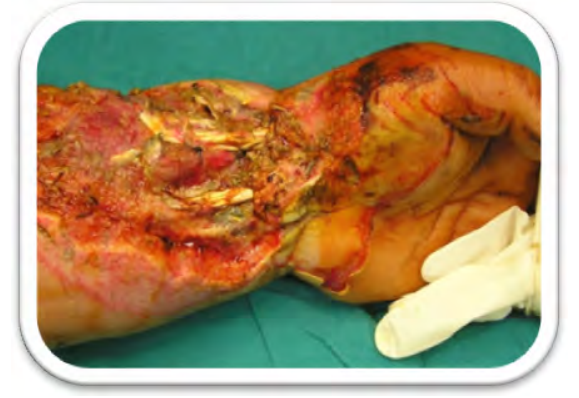

(A) an edematous swelling and volume increase in the flap was noticed during the first 2 - 4 weeks. From that time, a continuous decrease in flap volume was noted and during follow up the muscles had flattened by atrophy to a significant degree within 5 - 7 months. No secondary intervention for debulking of the muscle was needed in any of these cases.

In three cases, lower abdominal skin and subcutaneous fat were removed in a miniabdominoplasty fashion to obtain skin grafts. The skin grafts were harvested with a dermatom from the excised tissue while in the rest of patients 16 skin grafts were taken from the lateral aspect of the upper thigh. All patients were treated with postoperative anti microbial, adequate fluids, limb elevation, dextran and baby aspirin.

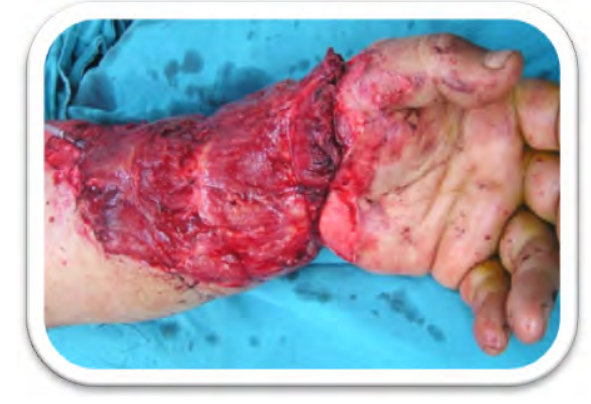

(B)

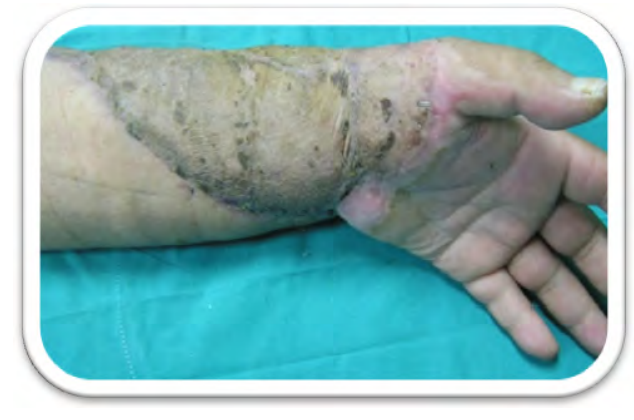

(C)

Figure (4): Showing A) Preoperative preparation of the reciepient site by good debridement, B) Coverge by free rectus flap, C) 6 ms post operative.

Complication included: Hematoma (1 case) which was later evacuated; ischemia occurred in one case where the hand was severely crushed and the patient was diabetic, revision of the arterial anastomosis was done and the flap vascularity was regained; another 2 cases showed early congestion of the flap as these patients were heavy smokers and hypertensive, revision of one vein was done, these revsions were done 6-9 hrs postoperatively. Infection occurred in one case which was treated by intravenous broad spectrum antibiotics and improvement occurred within 5 days. Disruption occurred in 2 cases where the original defect was $12 \mathrm{~cm}$ in width. The STSG showed 10\% loss in one case and $30 \%$ loss in another case; the first was left to heal conservatively while the other was rescheduled for re-grafting operation. 
As for the donor site, early complication showed seroma in 2 cases and wound disruption in one case which was left to heal conservatively. Lately, no affection was seen in trunk movement and abdominal bending. No incidence of hernia with traditional harvest except in one case which occurred after endoscopic harvest.

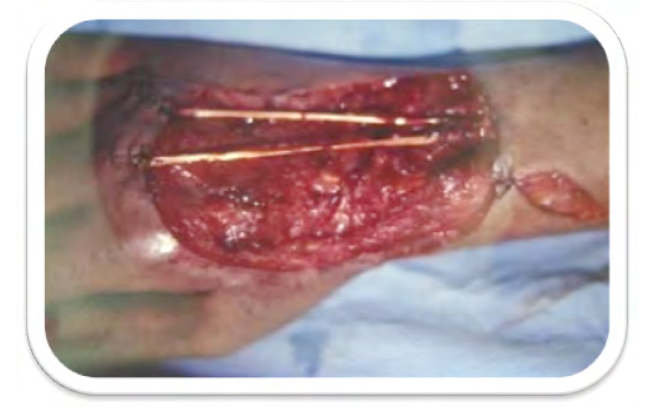

(A)
All covered areas remained stable and resistant against shear stress and allowed for good motion of underlying structures except in 4 cases where tendon grafting was done using part of the tensor fascia lata which needed 2nd stage tenolysis. Regain of sensation was seen after a period of 3-6months postoperatively. Bone union was judged by $\mathrm{X}$ rays on the hand that showed evidence of callus formation except for 1 case where debridement for the osteomyelitic bone was needed.

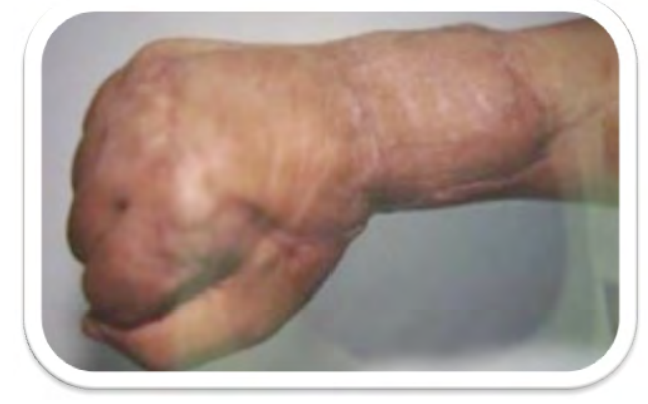

(B)

Figure (5): Showing a patient after degloving injury over the dorsum of the hand, A) Showing the hand after vigorous debridement, B) Reconstruction with free rectus abdominis with STSG 6 ms later.

\section{Discussion:}

Adequate soft tissue coverage is the main problem for any successful hand reconstruction. The options includes primary closure, skin grafts, local soft tissue flaps, regional pedicle and island flaps, free tissue transfer, composite free tissue transfers and perforator flaps which allow surgeons to cover skin and soft tissue defects. Good soft tissue coverage allows the early return of function and hand mobility. It also prevents infection and improves the quality of healing with less fibrosis and adhesions. Good soft tissue coverage enhances the nerve and tendon healing, also protects the vessels and allows early bone union. ${ }^{7}$

The development of microsurgery and the expansion of plastic surgery techniques increase the surgical options for the salvage of the upper extremities. Free flaps offer a great variety of available tissues to cover larger defects. It improves the perfusion in the infected areas. The treatment of choice depends on the site, dimensions and cause of the defect. ${ }^{12}$

For upper extremity reconstruction, there are variable flaps either local or distant for reconstruction e.g. radial forearm, posterior interosseous and lateral forearm flaps. The radial forearm flap based on the multiple cutaneous branches of the distal part of the radial artery was used to cover defects of the hand. In this flap, the major artery would be discarded. Furthermore, the cutaneous branches from the distal part of the radial artery could be used as pedicle, but they were too small to be anastomosed with higher incidence of donor site morbidity. ${ }^{13-15}$

The posterior interosseous flap colud be harvested as an island fasciocutaneous flap vascularized by branches of the posterior interosseous artery. It is used to cover skin loss around the wrist and the hand. The main disadvantage of the posterior interosseous flap lies in its relatively short pedicle, use for small defect, injury of posterior interooseous nerve and venous congestion of the flap. ${ }^{16,17}$ Latissimus dorsi muscle flap or myocutaneous flap can be used for upper limb reconstruction but its harvest need to put the patient in lateral position, so only one team can work at time, which increases the length of the operation and adds more dangers from the hazards of anesthesia. ${ }^{9}$ 
The rectus abdominis muscle flap is a long strap-like class III muscle. It receives main blood supply from the superior and inferior epigastric arteries in addition to a multisegmental blood supply from 6 or 7 intercostal and the subcostal vessels. It is a useful free flap for upper extremity defect reconstruction due to its vascular territory and the length and size of the vascular pedicle. It can be harvested in the supine position with large volume of tissue available using a lazy $\mathrm{L}$ incision or endoscopic ${ }^{18,19}$ and with low incidence of donor site morbidity. ${ }^{10,20}$

In our study, we concentrated mainly on reconstruction of the composite hand defects with the rectus abdominis muscle free flap. Our choice for this free flap was due to its big advantages in such cases.

- It can be harvested with the patient in supine position, which facilitates the work of two teams side by side (one for muscles harvest and the other for preparation of the recipient site). This has great advantage in minimizing the time of operation in those patients with acute injuries as some of them may suffer from another internal or external injury. So the proper choice of flap reconstruction in these cases plays a significant role in decreasing the time of anesthesia.

- Another important advantage is the relation between the size of the defect and the harvested muscle size (no defect in the 18 cases included in this study couldn't be covered by the rectus muscle). This was due to the fact that the width of the defect doesn't interfere with the width of the muscle even if this defect includes the whole dorsum of the hand which is larger than the normal size of the muscle. This was overcome by the fact that after harvest, the length of the muscle shortens and contracts approximately 30 percent from its original length. Similarly, the width of the muscle increases by approximately 25 - 50 percent.

- It also can be used as a vascular conduit which anastomose at a higher level than the zone of injury.

- It is a muscle flap which shrinks by time so no need for further sessions of debulking.

- Easy to harvest.

- Long pedicle length.

- Nearly equal caliber between the inferior epigastric vessels in relation with the radial or ulnar vessels.

- Donor site morbidity is very small even when harvested by endoscope.

The primary issue in microvascular tissue transfer is vascular access for vessel anastomosis. Although the upper extremity has a rich vascular supply, trauma may limit the available choices for anastomosis. In most patients, the hand will maintain adequate perfusion if only one of the major arteries (radial or ulnar) is open. ${ }^{21}$

In our study, we have good advantages for use of the same injured vessel but at a higher level ( $5 \mathrm{~cm}$ above the injury) which can be determined by angiography and intra operatively at the time of operation. So we do not scarifice the other vessel of the hand and maintain it in a good condition without adding further trauma to the supplying non crushed vessel. If distal part of the vessel is showing blood flow by angiography the anastomosis will be done end to side, which is safer, but if it showed no blood flow, end to end anastomosis will be done. Venous anastomosis is usually best done to one of the superficial veins of the forearm because the deep venous system is small and anastomosis may be difficult. A great care should be considerd if digital artery is injured because digital nerves pass on the palmar aspect of the vessel. So if the vessel is injured from a volar laceration then one can assume that the nerve is also injured and must be repaired.

The timing of soft tissue reconstruction in complex extremity injuries is important and still controversial. Yamauch et al. ${ }^{15}$ found no negative effect on the final results of delayed wound coverage after an average of 17 days and recommended serial debridements and saline dressings until definitive wound closure between 1 and 2 weeks following the injury. Godina and others 22 introduced the term 'emergency' free flaps, combining radical debridement of all poorly perfused or necrotic bone and soft tissue with a definitive bone fixation and flap coverage. Immediate, functional wound closure will decrease wound morbidity and without the bad effects of prolonged open wound treatment. These bad effects include; infection, dressing and delayed 
bone healing. Godina 22 reported on 532 microsurgical upper and lower extremity reconstructions and found total flap necrosis in $20 \%$ and postoperative infections in $29 \%$ when patients were treated beyond a critical period of $72 \mathrm{~h}$, contrary to rates of not more than $1 \%$ and $2 \%$, respectively, when bone, muscle and skin wounds were closed earlier.

They discussed radical debridement, a safe bone fixation and wound coverage using wellperfused muscle flaps as the most important factors of success. Giessler ${ }^{23}$ compared the results of 14 patients with an immediate soft tissue reconstruction within $24 \mathrm{~h}$ to 15 patients with delayed flap coverage at a mean interval of 4.4 days. They reported no bony infection in the first, but four cases in the delayed subgroup; furthermore bony union was not achieved in this delayed group until 11.6 months versus 5.6 months in the patients reconstructed within the first day. As a further advantage of early wound closure by one-stage procedures, it has been postulated that well perfused muscle flaps can cover an open fracture safely, prevent post-traumatic osteomyelitis and may promote early bony consolidation. ${ }^{11}$

The main causes of these complications were progressive tissue fibrosis and oedema and thus could largely be prevented by his very early and aggressive approach. Similarly, Gopal et al. ${ }^{24}$ reported on 84 patients of which $75 \%$ received soft tissue after reconstruction following radical debridement within $72 \mathrm{~h}$. Bony infection occurred in only $3 \%$ of patients treated within the first day, but increased to $10 \%$ and $30 \%$, respectively, if wound closure was performed between 24 and $72 \mathrm{~h}$ or beyond the first 3 days after injury.

In our study, our complication rate showed; hematoma (1 case), ischemia occurred in one case where the hand was severely crushed and the patient was diabetic, another 2 cases showed early congestion of the flap as these patients were heavy smokers and hypertensive, revision of one vein was done, these revisions were done 6-9 hrs postoperatively. Infection occurred in one case which was treated by intravenous broad spectrum antibiotics and improvement occurred within 5 days. Disruption occurred in 2 cases where the original defect was $\bullet 12$ $\mathrm{cm}$ in width. The rate of complications in early management (15 patients) were 2 patients, while in the late recovery, infection and disruption, occurred in 2 cases from a total of 3 cases. So the rate of complications is much higher in late reconstruction rather than early intervention. The STSG showed 10\% loss in one case and $30 \%$ loss in another case. The first was left to heal conservatively while the other was rescheduled for re-grafting operation. As for the donor site, early complication showed seroma in 2 cases and wound disruption in one case.

In our study, only in 3 cases we interfered late in the third weeks following the trauma (in two cases we received them in our department after 5 days from the trauma) with severe edema necrosis and infection. So classic debridement was done with regular dressing twice with saline, local autolytic enzymes and intravenous antibiotics according to culture and sensitivity. In one case the general condition did not allow us to interfere early (patient was severly hypertensive, diabetic and heavy smoker). In this patient we preferred to do it late to decrease the risk of free flap failure.

Many authors tried to perform a post operative functional outcome scoring system; Durham ${ }^{25}$ studied indirect measures of severity such as number of operations, number of admissions, and number of days spent in hospital and dominance of the injured hand. The short follow-up of 2 months meant that the final work status could not be accurately established. The modified hand injury scoring system (MHISS) is proposed as an aid to determining prognosis rather than treatment. Finally, recent advances in limb salvage have made it possible to save severely damaged extremities that would have been amputated in the past. Several different scoring systems have been made to help the surgeon decide which limbs should be salvaged and which should undergo primary amputation. None of the scores was able to discriminate between patients with good and poor functional outcomes. So, we need in our further studies to provide a reliable scoring system for upper extremity injuries. 


\section{References:}

1- Pederson WC: Upper extremity microsurgery. Plast Reconstr Surg 2001; 107(6): 1524-1537.

2- Sabapathya SR, Bhardwaj P: Skin cover in hand injuries. Current Orthopaedics 2008; 22: 1-8.

3- Sakai S: Free flap from the flexor aspect of the wrist for resurfacing defects of the hand and fingers. Plast Reconstr Surg 2003; 111(4): 1412-1420.

4- Daniel RK, Taylor GI: Distant transfer of an island flap by microvascular anastomoses: A clinical technique. Plast Reconstr Surg 1973; 52: 111.

5- Steiert AE, Gohritz AY, Schreiber TC, Krettek C, Vogt PM: Delayed flap coverage of open extremity fractures after previous vacuum-assisted closure (VAC) therapyworse or worth? J Plast Reconstr Aesth Surg 2009; 62: 675-683.

6- Godina, M: Wound care and timing of microvascular flap transfer to the lower leg. In: A thesis on the management of injuries to the lower extremity. Ljubljana: Presernova Druzba; 1991; p.77-84.

7- Graft P, Steinau HU, Ingianni G, Biemer E: The pros and cons of distant pedicled flaps for upper extremity trauma reconstruction in the era of microvascular surgery. Eur $J$ Plast Surg 1991; 14: 288-293.

8- Braun FM, Hoang P, Merle M, van Genechten F, Foucher G: Technique and indications of the forearm flap in hand surgery: A report of thirty-three cases. Ann Chir Main 1985; 4: 85.

9- Park C, Shin K S: Functioning free latissimus dorsi muscle transplantation: Anterogradely positioned usage in reconstruction of extensive forearm defect. Ann Plast Surg 1991; 27: 87.

10-Mathes SJ, Nahai F: The rectus abdominis flap. Reconstructive surgery: Principles, anatomy and technique, Vol. 2. New York: Churchill Livingstone Inc. (Publisher); 1997; p. 1043-1083.

11-Chen CM, Halvorson EG, Disa JJ, McCarthy C, Hu QY, Pusic AL, Cordeiro PG, Mehrara BJ: Immediate postoperative complications in DIEP versus free/musclesparing TRAM flaps. Plast Reconstr Surg 2007; 120(6): 1477-1482.
12-El-Shazly M, Makboul M: Microsurgical free tissue transfer as a valuable reconstructive procedure in foot reconstruction. Indian J Plast Surg 2007; 40: 141-146.

13-Ahn HC, Choi MS, Hwang WJ, Sung KY: The transverse radial artery forarm flap. Plast Reconstr Surg 2007; 119: 2153-2160.

14-Soutar DS, Tanner NSB: The radial forearm flap in the management of soft tissue injuries of the hand. Br J Plast Surg 1984; 37: 18.

15-Yajima H, Tamai S, Yamauchi T, Mizumoto S: Osteocutaneous radial forearm flap for hand reconstruction. J Hand Surg (Am) 1999; 24: 594.

16-Brunelli F, Valenti P, Dumontier C, Panciera $\mathrm{P}$ : The posterior interosseous reverse flap: Experience with 113 flaps. Annals of Plastic Surgery 2001; 47(1).

17-Chen HC, Tang YB, Chuang D, Wei FC, Noordhoff MS: Microvascular free posterior interosseous flap and a comparison with the pedicled posterior interosseous flap. Ann Plast Surg 1996; 36: 542.

18-Miller MJ, Robb GL: Endoscopic techniques for free flap harvest. Clin Plast Surg 1995; 22: 755.

19-Rodriguez ED, Mithani SK, Langner RB, Manson PN: Hand evaluation following ulnar forearm perforator flap harvest: A prospective study. Plast Reconstr Surg 2007; 120(6): 1598-1601.

20-Khalil HH, El-Ghoneimy A, Farid Y, Ebeid W, Afifi A, El-Affandi A, Mahboub T: Modified vertical rectus abdominis musculocutaneous flap for limb salvage procedures in proximal lower limb musculoskeletal sarcomas. Sarcoma 2008; Article ID 781408. Published online doi: 10.1155/2008/781408.

21-Bass LS, Karp NS, Benacquista T, Kasabian AK: Endoscopic harvest of the rectus abdominis free flap: Balloon dissection in the fascial plane. Ann Plast Surg 1995; 34: 274.

22-Godina M: Early microsurgical reconstruction of complex trauma of the extremities. Plast Reconstr Surg 1986; 78 : 285-296. 
23-Giessler GA, Erdmann D, Germann G: Soft tissue coverage in devastating hand injuries. Hand Clin 2003; 19: 63-71.

24-Gopal S, Majumder S, Batchelor AGB, et al: Fix an Flap. J Bone Joint Surg Br 2000; 82: 959-966.
25-Durham RN, Bhargav MM, Mazuski JE, Shapiro M, Jacobs D: Outcome and utility of scoring systems in the management of the mangled extremity. Am J Surg 1996; 172: 569-574. 